\title{
Prognostic value of lymph node ratio and extramural vascular invasion on survival for patients undergoing curative colon cancer resection
}

\author{
C N Parnaby ${ }^{*}, 1$ N W Scott ${ }^{2}$, G Ramsay ${ }^{1}$, C MacKay ${ }^{1}$, L Samuel ${ }^{3}$, G I Murray ${ }^{4}$ and M A Loudon ${ }^{1}$ \\ ${ }^{1}$ Department of Surgery, Aberdeen Royal Infirmary, Aberdeen, UK; ${ }^{2}$ Medical Statistics Team, University of Aberdeen, Aberdeen, \\ UK; ${ }^{3}$ Department of Oncology, Aberdeen Royal Infirmary, Aberdeen, UK and ${ }^{4}$ Department of Pathology, Aberdeen Royal \\ Infirmary, Aberdeen, UK
}

Background: Increasing lymph node ratio (LNR) (ratio of metastatic lymph nodes to the total number of harvested lymph nodes) and extramural vascular invasion (EMVI) have been proposed as adverse prognostic indicators in colorectal cancer, although their use remains variable and controversial. The aim of the present study was to assess the prognostic value of LNR and EMVI in predicting survival for patients undergoing curative colon cancer resection.

Methods: Between 2006 and 2012, 922 patients underwent curative colon cancer resection. Surgical technique and pathological assessment did not change during the study period. Clinical and pathological data were collected from a prospectively maintained database. The primary outcome measure was overall survival and disease-free survival. LNR was separated into five categories based on three previously calculated cutoff values: LNR 0 (no lymph nodes involved), LNR 1 (ratio $0.01<0.17$ ), LNR 2 (ratio 0.18-0.41), LNR 3 (ratio 0.42-0.69), and LNR 4 (ratio >0.70).

Results: Nine hundred and twenty-two patients underwent colon cancer resection. The median follow-up for survivors was 52.8 months (IQR 34.6-77.6). The median total number of lymph nodes harvested was 16 (IQR13-22). On multivariate analysis, both pN and LNR were strongly associated with overall and disease-free survival. Using the Akaike information criterion (AIC), LNR had greater prognostic value compared with $\mathrm{pN}$. For overall survival, compared with patients in LNR category 0, hazard ratios $(95 \% \mathrm{Cl})$ for those in categories 1, 2,3 and 4 were $1.37(1.03,1.82), 2.37(1.70,3.30), 2.40(1.57,3.65)$ and $5.51(3.16,9.58)$, respectively. For disease-free survival, patients had hazard ratios $(95 \% \mathrm{Cl})$ of $1.78(1.25,2.52), 3.79(2.56,5.61), 2.60(1.50,4.48)$ and $4.76(2.21,10.27)$, respectively. The presence of EMVI was a significant predictor of decreased overall and disease-free survival $(P<0.001)$.

Conclusions: This study demonstrated, in the presence of high surgical, oncology and pathological standards, EMVI and increasing LNR were independent predictors of decreased overall and disease-free survival for patients undergoing curative colon cancer resection. LNR was superior to $\mathrm{pN}$ stage in predicting overall and disease-free survival.

Colorectal cancer is the third most common cancer in Europe and North America (International Agency for Research on Cancer, 2008). Pathological staging not only provides important prognostic information but also are used to inform discussions and decisions on the use of adjuvant chemotherapy. The most widely used colorectal staging tool is the TNM (tumours/nodes/metastases) system (Sobin and Wittekind, 1997). The fifth edition of TNM (TNM 5), introduced in 1995, is still predominantly used in the 
United Kingdom to ensure consistency and comparability of data. Subsequent revisions have not demonstrated an improvement on prognosis (Ueno et al, 2012).

The presence of lymph node metastases are an important prognostic factor for survival of patients with colonic cancer. The current $\mathrm{pN}$ stage classifies patients into three categories: $\mathrm{pN} 0$ (no lymph node metastases), pN1 (1-3 lymph node metastases), and $\mathrm{pN} 2$ ( $>4$ lymph node metastases). A number of studies have suggested the lymph node ratio (LNR) (defined as the ratio of metastatic lymph nodes to the total number of harvested lymph nodes) is a superior prognostic factor compared with the $\mathrm{pN}$ stage (Berger et al, 2005; Rosenberg et al, 2008; Moug et al, 2011; Lykke et al, 2013). These studies have demonstrated the marked changes in survival within the $\mathrm{pN} 1$ or $\mathrm{pN} 2$ categories depending on the value of LNR. A number of concerns remain, for example: the LNR categories were arbitrarily defined, colon and rectal cancer were analysed together, pathological assessment changed over time, the study period covered a large timeframe, or the use of adjuvant chemotherapy was not reported.

Additional pathological features have been identified as adverse prognostic indicators for survival in patients undergoing potential curative surgery for colorectal cancer. Extramural vascular invasion (EMVI) has been reported to be an important adverse prognostic indicator (Courtney et al, 2009; Bhangu et al, 2013). Detection of EMVI may help improve selection of patients who would benefit from adjuvant chemotherapy. EMVI is one of the core parameters to be reported in the minimum data set for colorectal cancer histopathology reporting as described by the Royal College of Pathologists (Williams et al, 2007). Despite this, the detection of EMVI remains highly variable between pathologists (Quirke and Morris, 2007).

The aim of the present study was to compare the ability of LNR, EMVI and other pathological factors in predicting overall survival and disease-free survival for patients undergoing curative colon cancer resection.

\section{MATERIALS AND METHODS}

Inclusion criteria. All patients undergoing curative colon adenocarcinoma resection from 2006 to 2012 were included. This included all patients undergoing elective or emergency surgery. Colon cancer was defined as a cancer $>15 \mathrm{~cm}$ from the anal verge. Tumour site was separated into proximal and distal tumours. Proximal colon cancers were defined proximal to the splenic flexure. Distal colon cancers were defined as involving splenic flexure to the rectosigmoid junction. Curative colon cancer resection was defined as no evidence of metastases on computed tomography $(\mathrm{CT})$ of the chest, abdomen and pelvis and curative tumour resection (R0) on pathology assessment.

Patients with metastases, concurrent malignancy and rectal cancers $(<15 \mathrm{~cm}$ from the anal verge) were excluded from the study.

Data collection. Data on patient demographics and tumour characteristics were obtained from a prospectively maintained database. Survival data were collated by analysis of a weekly updated local cancer registry. Adjuvant chemotherapy data were collected by retrospective review of patient electronic records. All patients were subject to multidisciplinary review following colonic resection. The primary outcomes were overall survival (the time from surgery to the date of death from any cause) and disease-free survival (the time to death or the discovery of local recurrence or regional metastasis on follow-up).

Data on age, gender, tumour site, tumour differentiation, TNM classification, lymph node yield, total number of tumour involved lymph nodes, LNR, EMVI, adjuvant chemotherapy, overall survival and disease-free survival were collected. LNR was defined as the ratio of number of metastatic lymph nodes/total number of harvested lymph nodes. LNR was separated into five categories based on three previously calculated cutoff values for LNRs that had the highest prognostic discrimination of survival in a cohort of 3026 patients with colon and rectal cancer (Rosenberg et al, 2008): $\mathrm{LNR}=0$ (no lymph nodes involved), $\mathrm{LNR}=1$ (ratio 0.01-0.17), $\mathrm{LNR}=2$ (ratio 0.18-0.41), $\mathrm{LNR}=3$ (ratio 0.42-0.69), and $\mathrm{LNR}=4$ (ratio $>0.70)$. These values have been validated on a populationbased study of colorectal cancer patients (Rosenberg et al, 2010). Patients with no lymph nodes involved $(\mathrm{LNR}=0)$ were included in the study to compare survival outcomes with the other four LNR categories both in the main analyses and sub group analyses.

Clinical management. All patients were subject to multidisciplinary review following colonic resection. Clinical assessment and staging was based on endoscopic evaluation and CT of the chest, abdomen and pelvis. Operative technique did not change during the study period and consisted of complete mesocolic mobilisation and division of the supplying arteries at their origin. For rightsided colon cancer resection, more radical mobilisation as described by Hohenberger et al (2009), involving mesenteric root, duodenum and pancreatic head mobilisation was not routinely performed.

Histopathological assessment of the colonic cancer excision specimens followed a uniform protocol throughout the study period. The colonic cancer excision specimens were received fresh in the diagnostic histopathological laboratory, opened along the antimesenteric border proximal and, when appropriate distal to the tumour, washed in cold water and then fixed in 10\% neutral buffered formalin for at least $48 \mathrm{~h}$ at room temperature prior to further dissection and block selection. Representative tissue blocks were embedded in wax, sections were then stained with haematoxylin and eosin for histopathological diagnosis and when required tumour sections were also stained with elastic haematoxylin and eosin to permit further assessment of EMVI. The tumours were reported according to the guidelines of Royal College of Pathologists for the histopathological reporting of colorectal cancer resection specimens, which incorporates guidance from version five of the TNM staging system (Williams et al, 2007).

The follow-up programme included outpatient visits every 6 months for 3 years. Blood was takn at these visits to measure liver function and carcinoembryonic antigen. Imaging was annual CT scanning (thorax, abdomen and pelvis), with 6 monthly interval abdominal ultrasound scanning. A follow-up colonoscopy was performed at 5 years unless it was incomplete at preoperative assessment. If this occurred, a repeat colonoscopy was performed in the postoperative period.

Adjuvant chemotherapy was considered for fit patients with adverse prognostic factors, such as the presence of metastatic lymph nodes, the presence of EMVI, serosal involvement or poorly differentiated tumours. The majority of patients with colon cancer were age $>70$ years, any decision on the use of adjuvant chemotherapy considered co-morbidities and the reduced physiological reserve of an older population of patients. During the study period, suitable patients were offered participation into adjuvant chemotherapy trials. These were the AVANT study (de Gramont et al, 2012) and the SCOT study (SCOT-Short Course Oncology Therapy, 2007). Outside of these trials, suitable patients would have been considered for oxaliplatin combined with folinic acid/5FU or capecitabine.

Statistical analysis. The effect of sex, tumour site, tumour grade, T stage, N stage, adjuvant chemotherapy, LNR and EMVI on overall survival and disease-free survival was first examined individually using Kaplan-Meier survival analysis. Differences in survival between categories were assessed using the log-rank test. 
The joint effect of these variables upon overall survival was then examined in a multivariate analysis using Cox's proportional hazards regression models. As LNR category and $\mathrm{pN}$ are correlated measures of lymph node status, separate models were developed for each. These models also controlled for age, EMVI, site, T stage, tumour grade and adjuvant chemotherapy.

The Akaike information criterion (AIC) provides an objective way of determining which model among a set of models is best for a given set of data, with the model with the lowest AIC being the best for the given data. In the present manuscript, AIC was used to determine the relative prognostic performance of $\mathrm{pN}$ and LNR models on overall survival and disease-free survival. The model with the lowest AIC gives the best prognostic value for predicting overall survival and disease-free survival.

Subgroup analyses by EMVI status were also examined using Cox's proportional hazards regression models. These models again controlled for adjuvant chemotherapy, age, site, $\mathrm{pT}$ stage and tumour grade.

All analyses were performed using IBM SPSS version 22. A $P$-value $<0.05$ was used as the level of significance.

Ethics. The project was carried out using anonymised data and within the remit of ethics approval (ref. nos. 08/S0801/81) from the North of Scotland research ethics committee.

\section{RESULTS}

Nine hundred and twenty-two patients with colon cancer underwent curative resection. One patient was excluded from the study as data on overall survival, local recurrence or metastatic disease were not available. The median follow-up for survivors was 52.8 months (IQR 34.6-77.6). During the followup period, 345 out of 921 (37.4\%) patients died. Local or metastatic disease was detected in 233 out of the 921 (25.2\%) patients. Clinical, pathological and chemotherapy data are shown in Tables 1 and 2. The median total number of lymph nodes harvested was 16 (IQR 13-22). The number of patients with $\geqslant 12$ lymph nodes was 776 (84.2\%). EMVI was present in 260 (28.0\%) patients.

Univariate analysis. Univariate analysis using the log-rank test identified the following parameters as statistically significant predictors of improved overall survival and disease-free survival: well or moderate tumour differentiation $(P=0.002)$, lower $\mathrm{pT}$ category $(P<0.001)$, distal tumour site $(P=0.02)$, lower $\mathrm{pN}$ category $(<0.001)$, lower LNR $(<0.001)$ (Figures 1 and 2$)$, absence of EMVI $(P<0.001)$, and elective surgery $(P<0.001)$.

Table 1. Clinical, histopathology and adjuvant chemotherapy characteristics and Cox proportional hazard models predicting overall survival for patients undergoing curative colon cancer resection

\begin{tabular}{|c|c|c|c|c|c|}
\hline & & \multicolumn{2}{|c|}{ Model One (including pN) $(n=921)$} & \multicolumn{2}{|c|}{ Model Two (including LNR) $(n=921)$} \\
\hline Variable & Patient demographics & Hazard ratio $(95 \% \mathrm{Cl})$ & $P$-value & Hazard ratio $(95 \% \mathrm{Cl})$ & $P$-value \\
\hline Age, years & $\begin{array}{c}75(66-82) \\
\text { (median (IQR)) }\end{array}$ & $1.02(1.00,1.03)$ & 0.007 & $1.01(1.00,1.03)$ & 0.007 \\
\hline \multicolumn{6}{|l|}{ Site } \\
\hline $\begin{array}{l}\text { Proximal } \\
\text { Distal }\end{array}$ & $\begin{array}{l}540(58.3 \%) \\
381(41.2 \%)\end{array}$ & $\begin{array}{c}1 \\
0.83(0.66,1.05)\end{array}$ & 0.12 & $\begin{array}{c}1 \\
0.86(0.68,1.08)\end{array}$ & 0.20 \\
\hline \multicolumn{6}{|l|}{ Tumour grade } \\
\hline $\begin{array}{l}\text { Well/moderate }{ }^{a} \\
\text { Poor/mucinous }\end{array}$ & $\begin{array}{l}791(85.9 \%) \\
130(14.1 \%)\end{array}$ & $\begin{array}{c}1 \\
1.37(1.04,1.82) \\
\end{array}$ & 0.03 & $\begin{array}{c}1 \\
1.37(1.03,1.82) \\
\end{array}$ & 0.03 \\
\hline \multicolumn{6}{|l|}{ T stage } \\
\hline $\begin{array}{l}1^{\mathrm{a}} \\
2 \\
3 \\
4\end{array}$ & $\begin{array}{c}53(5.7 \%) \\
82(8.9 \%) \\
576(62.2 \%) \\
210(22.7 \%)\end{array}$ & $\begin{array}{c}1 \\
1.17(0.53,2.59) \\
1.19(0.60,2.36) \\
1.93(0.94,3.92)\end{array}$ & 0.001 & $\begin{array}{c}1 \\
1.11(0.50,2.48) \\
1.15(0.58,2.27) \\
1.84(0.90,3.75)\end{array}$ & 0.002 \\
\hline \multicolumn{6}{|l|}{$\mathrm{N}$ stage } \\
\hline $\begin{array}{l}0^{\mathrm{a}} \\
1 \\
2\end{array}$ & $\begin{array}{l}510(55.4 \%) \\
270(29.3 \%) \\
141(15.3 \%)\end{array}$ & $\begin{array}{c}1 \\
1.52(1.17,1.99) \\
2.40(1.76,3.28)\end{array}$ & $<0.001$ & $\begin{array}{l}\text { NA } \\
\text { NA } \\
\text { NA }\end{array}$ & \\
\hline \multicolumn{6}{|l|}{ Lymph node ratio } \\
\hline $\begin{array}{l}\text { LNR }^{\text {a }} \\
\text { LNR } 1(0.01-0.17) \\
\text { LNR } 2(0.18-0.41) \\
\text { LNR } 3(0.42-0.69) \\
\text { LNR } 4(>0.7)\end{array}$ & $\begin{array}{c}510(55.4 \%) \\
243(26.4 \%) \\
105(11.4 \%) \\
42(4.6 \%) \\
21(2.3 \%)\end{array}$ & $\begin{array}{l}\text { NA } \\
\text { NA } \\
\text { NA } \\
\text { NA } \\
\text { NA }\end{array}$ & & $\begin{array}{c}1 \\
1.37(1.03,1.82) \\
2.37(1.70,3.30) \\
2.40(1.57,3.65) \\
5.51(3.16,9.58)\end{array}$ & $<0.001$ \\
\hline \multicolumn{6}{|l|}{ Extramural vascular invasion } \\
\hline $\begin{array}{l}\mathrm{No}^{\mathrm{a}} \\
\text { Yes }\end{array}$ & $\begin{array}{l}661(71.4 \%) \\
260(28.0 \%)\end{array}$ & $\begin{array}{c}1 \\
2.08(1.62,2.68)\end{array}$ & $<0.001$ & $\begin{array}{c}1 \\
1.98(1.54,2.56)\end{array}$ & $<0.001$ \\
\hline \multicolumn{6}{|l|}{ Adjuvant chemotherapy } \\
\hline $\begin{array}{l}\mathrm{No}^{\mathrm{a}} \\
\text { Yes }\end{array}$ & $\begin{array}{l}750(81.5 \%) \\
171(18.5 \%)\end{array}$ & $\begin{array}{c}1 \\
0.62(0.42,0.91)\end{array}$ & 0.01 & $\begin{array}{c}1 \\
0.61(0.41,0.89)\end{array}$ & 0.01 \\
\hline Total number of lymph nodes & $\begin{array}{c}16(13-22) \\
\text { (median (IQR)) }\end{array}$ & $0.98(0.96,0.99)$ & 0.005 & $0.99(0.97,1.00)$ & 0.13 \\
\hline \multicolumn{6}{|l|}{ Emergency status } \\
\hline $\begin{array}{l}\text { Elective }^{\mathbf{a}} \\
\text { Emergency }\end{array}$ & $\begin{array}{l}739(80.2 \%) \\
182(19.8 \%)\end{array}$ & $\begin{array}{c}1 \\
2.43(1.91,3.11)\end{array}$ & $<0.001$ & $\begin{array}{c}1 \\
2.53(1.98,3.23)\end{array}$ & $<0.001$ \\
\hline
\end{tabular}


Table 2. Clinical, histopathology and adjuvant chemotherapy characteristics and Cox proportional hazard models predicting disease-free survival for patients undergoing curative colon cancer resection

\begin{tabular}{|c|c|c|c|c|c|}
\hline \multirow{2}{*}{ Variable } & \multirow[b]{2}{*}{ Patient demographics } & \multicolumn{2}{|c|}{ Model One (including pN) $(n=921)$} & \multicolumn{2}{|c|}{ Model Two (including LNR) $(n=921)$} \\
\hline & & Hazard ratio $(95 \% \mathrm{Cl})$ & $P$-value & Hazard ratio $(95 \% \mathrm{Cl})$ & $P$-value \\
\hline Age, years & $\begin{array}{c}75(66-82) \\
\text { (median (IQR)) }\end{array}$ & $0.99(0.97,1.00)$ & 0.07 & $0.99(0.98,1.00)$ & 0.10 \\
\hline \multicolumn{6}{|l|}{ Site } \\
\hline $\begin{array}{l}\text { Proximal }^{a} \\
\text { Distal }\end{array}$ & $\begin{array}{l}540(58.3 \%) \\
381(41.2 \%)\end{array}$ & $\begin{array}{c}1 \\
0.91(0.69,1.19) \\
\end{array}$ & 0.48 & $\begin{array}{c}1 \\
0.95(0.72,1.25) \\
\end{array}$ & 0.69 \\
\hline \multicolumn{6}{|l|}{ Tumour grade } \\
\hline $\begin{array}{l}\text { Well/moderate }{ }^{a} \\
\text { Poor/mucinous }\end{array}$ & $\begin{array}{l}791(85.9 \%) \\
130(14.1 \%) \\
\end{array}$ & $\begin{array}{c}1 \\
1.22(0.86,1.73) \\
\end{array}$ & 0.27 & $\begin{array}{c}1 \\
1.29(0.90,1.83) \\
\end{array}$ & 0.16 \\
\hline \multicolumn{6}{|l|}{ T stage } \\
\hline $\begin{array}{l}1^{\mathrm{a}} \\
2 \\
3 \\
4\end{array}$ & $\begin{array}{c}53(5.7 \%) \\
82(8.9 \%) \\
576(62.2 \%) \\
210(22.7 \%) \\
\end{array}$ & $\begin{array}{c}1 \\
0.87(0.28,2.77) \\
1.78(0.72,4.42) \\
2.91(1.14,7.44)\end{array}$ & 0.001 & $\begin{array}{c}1 \\
0.84(0.26,2.65) \\
1.69(0.68,4.18) \\
2.82(1.10,7.20)\end{array}$ & 0.001 \\
\hline \multicolumn{6}{|l|}{$\mathrm{N}$ stage } \\
\hline $\begin{array}{l}0^{a} \\
1 \\
2 \\
\end{array}$ & $\begin{array}{l}510(55.4 \%) \\
270(29.3 \%) \\
141(15.3 \%) \\
\end{array}$ & $\begin{array}{c}1 \\
1.96(1.40,2.73) \\
3.35(2.28,4.92) \\
\end{array}$ & $<0.001$ & $\begin{array}{l}\text { NA } \\
\text { NA } \\
\text { NA }\end{array}$ & \\
\hline \multicolumn{6}{|l|}{ Lymph node ratio } \\
\hline $\begin{array}{l}\text { LNR }^{\text {a }} \\
\text { LNR } 1(0.01-0.17) \\
\text { LNR } 2(0.18-0.41) \\
\text { LNR } 3(0.42-0.69) \\
\text { LNR } 4(>0.7)\end{array}$ & $\begin{array}{c}510(55.4 \%) \\
243(26.4 \%) \\
105(11.4 \%) \\
42(4.6 \%) \\
21(2.3 \%) \\
\end{array}$ & $\begin{array}{l}\text { NA } \\
\text { NA } \\
\text { NA } \\
\text { NA } \\
\text { NA }\end{array}$ & & \begin{tabular}{l}
\multicolumn{1}{c}{1} \\
$1.78(1.25,2.52)$ \\
$3.79(2.56,5.61)$ \\
$2.60(1.50,4.48)$ \\
$4.76(2.21,10.27)$
\end{tabular} & $<0.001$ \\
\hline \multicolumn{6}{|l|}{ Extramural vascular invasion } \\
\hline $\begin{array}{l}\mathrm{No}^{\mathrm{a}} \\
\text { Yes }\end{array}$ & $\begin{array}{l}661(71.4 \%) \\
260(28.0 \%)\end{array}$ & $\begin{array}{c}1 \\
2.10(1.55,2.83)\end{array}$ & $<0.001$ & $\begin{array}{c}1 \\
2.08(1.54,2.81)\end{array}$ & $<0.001$ \\
\hline \multicolumn{6}{|l|}{ Adjuvant chemotherapy } \\
\hline $\begin{array}{l}\mathrm{No}^{\mathrm{a}} \\
\text { Yes }\end{array}$ & $\begin{array}{l}750(81.5 \%) \\
171(18.5 \%)\end{array}$ & $\begin{array}{c}1 \\
0.73(0.49,1.09) \\
\end{array}$ & 0.12 & $\begin{array}{c}1 \\
0.70(0.47,1.05) \\
\end{array}$ & 0.09 \\
\hline Total number of lymph nodes & $\begin{array}{c}16(13-22) \\
\text { (median (IQR)) }\end{array}$ & $0.98(0.96,1.00)$ & 0.02 & $0.99(0.97,1.01)$ & 0.22 \\
\hline \multicolumn{6}{|l|}{ Emergency status } \\
\hline $\begin{array}{l}\text { Elective }^{a} \\
\text { Emergency }^{-}\end{array}$ & $\begin{array}{l}739(80.2 \%) \\
182(19.8 \%)\end{array}$ & $\begin{array}{c}1 \\
1.88(1.39,2.54)\end{array}$ & $<0.001$ & $\begin{array}{c}1 \\
1.90(1.40,2.57)\end{array}$ & $<0.001$ \\
\hline
\end{tabular}

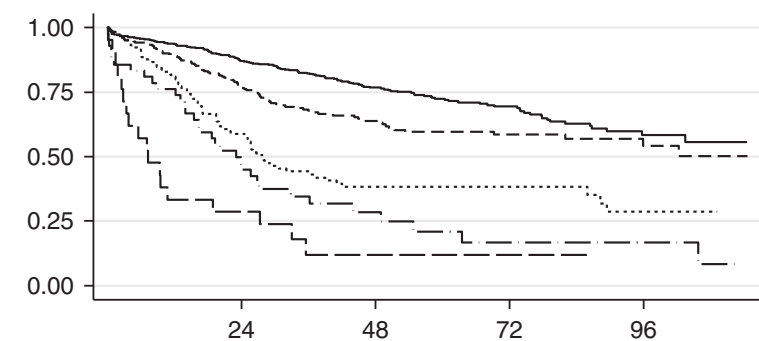

Time from operation to death or last follow-up (months)

Number at risk

\begin{tabular}{lccccc} 
LNR1 $=0$ & 511 & 410 & 239 & 118 & 39 \\
LNR1 $=1$ & 243 & 169 & 91 & 47 & 21 \\
LNR1 $=2$ & 105 & 59 & 30 & 21 & 6 \\
LNR1 $=3$ & 42 & 18 & 8 & 3 & 2 \\
LNR1 $=4$ & 21 & 6 & 2 & 1 & 0 \\
& & & \\
\hline & & &
\end{tabular}

Figure 1. Overall survival by lymph node ratio category (LNR 0-4) for patients undergoing curative colon cancer resection.

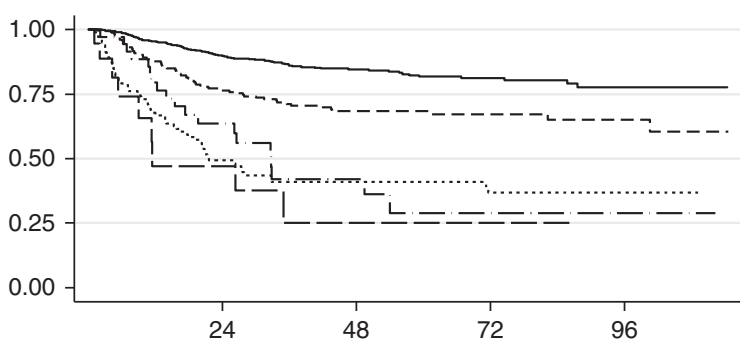

Time from operation to death or last follow-up (months)

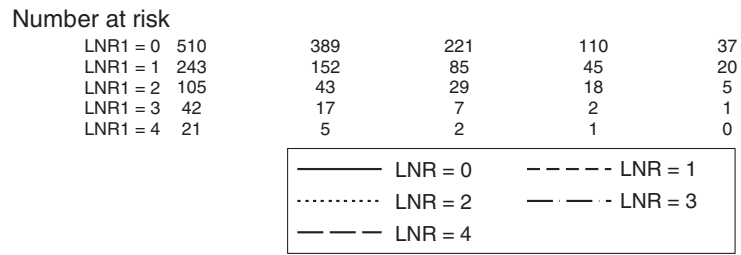

Figure 2. Disease-free survival by lymph node ratio category (LNR 0-4) for patients undergoing curative colon cancer resection. 
Adjuvant chemotherapy and sex were not statistically significant predictors of overall mortality $(P=0.065$ and $P=0.381$, respectively).

Multivariate analysis. Table 2 shows the results of the two Cox regression models for overall survival, one including $\mathrm{pN}$ and the other LNR category. Table 3 shows the results of the corresponding Cox regression models for disease-free survival. There was strong evidence that, after controlling for other variables, both $\mathrm{N}$ stage and LNR category were associated with overall survival and disease-free survival. For overall survival, compared with patients with $\mathrm{pN} 0$, those with $\mathrm{pN} 1$ and 2 had hazard ratios (95\% CI) of $1.52(1.17,1.99)$ and $2.40(1.76,3.28)$, respectively. For disease-free survival, patients had hazard ratios $(95 \% \mathrm{CI})$ of $1.96(1.40,2.73)$ and $3.55(2.28,4.92)$, respectively.

For overall survival, compared with patients in LNR category 0 , hazard ratios $(95 \% \mathrm{CI})$ for those in categories $1,2,3$ and 4 were 1.37 (1.03, 1.82), 2.37 (1.70, 3.30), $2.40(1.57,3.65)$ and $5.51(3.16$, 9.58), respectively. For disease-free survival, patients had hazard ratios $(95 \% \mathrm{CI})$ of $1.78(1.25,2.52), 3.79(2.56,5.61), 2.60$ (1.50, $4.48)$ and $4.76(2.21,10.27)$, respectively.

The multivariate analyses identified the presence of EMVI as a statistically significant predictor of decreased overall and diseasefree survival $(P<0.001)$.

Other parameters associated with statistically significant decreased overall and disease-free survival included: higher $\mathrm{pT}$ category and emergency surgery. The administration of adjuvant chemotherapy was a significant predictor of improved overall survival but not disease-free survival in the adjusted analysis.

Using $\mathrm{pN}$ in the Cox regression model, the total number of lymph nodes harvested was associated with significant decreased overall and disease-free survival. This association was not present when LNR was used in the model.

Prognostic value of $\mathrm{LNR}$ and $\mathrm{pN}$ on overall survival. The AIC was used to determine the relative performance of $\mathrm{pN}$ and LNR. LNR model was found to have lower AIC values for both overall survival (13.1 points) and disease-free survival (4.4 points), indicating that LNR may have the greater prognostic value (Table 4).

Subgroup analysis. The relationship of LNR and EMVI on overall survival was evaluated using subgroup analyses. Separate Cox's

Table 3. Prognostic value of $\mathrm{pN}$ and LNR on overall survival using Akaike information criterion (AIC)

\begin{tabular}{|l|c|}
\hline & AIC \\
\hline Base model $^{\text {a }}$ & 4169.5 \\
\hline Base model plus pN & 4144.1 \\
\hline Base model plus LNR & 4131.0 \\
\hline $\begin{array}{l}\text { Abbreviation: LNR = lymph node ratio. } \\
\text { a Base model is a Cox proportional hazards model including the following variables: age, } \\
\text { site, grade, T stage, extramural vascular invasion, adjuvant chemotherapy, total nodes, and } \\
\text { emergency status. }\end{array}$ \\
\hline
\end{tabular}

Table 4. Prognostic value of $\mathrm{pN}$ and LNR on disease-free survival using Akaike information criterion (AIC)

\begin{tabular}{|l|c|}
\hline & AIC \\
\hline Base model $^{\text {a }}$ & 2866.9 \\
\hline Base model plus pN & 2832.7 \\
\hline Base model plus LNR & 2828.3 \\
\hline $\begin{array}{l}\text { Abbreviation: LNR =lymph node ratio. } \\
\text { a Base model is a Cox proportional hazards model including the following variables: age, } \\
\text { site, grade, T stage, extramural vascular invasion, adjuvant chemotherapy, total nodes, and } \\
\text { emergency status. }\end{array}$ \\
\hline
\end{tabular}

proportional hazard regression models were performed for the LNR categories in patients with and without EMVI (Figures 3 and 4). LNR categories 2, 3 and 4 were combined because of small numbers in these individual categories.

Patients with EMVI had a worse overall survival. For both subgroups (those with and without EMVI), there was a similar statistically significant relationship $(P<0.001)$ between LNR categories (LNR 0, LNR 1 and LNR 2-4) and overall survival (Figures 3 and 4).

\section{DISCUSSION}

The present study has shown LNR and EMVI were independent predictors of overall and disease-free survival for patients undergoing curative colon cancer resection. LNR category was of greater prognostic value for predicting overall survival compared with $\mathrm{pN}$ category.

A number of studies have reported the prognostic value of LNR in predicting survival for patients undergoing colorectal cancer

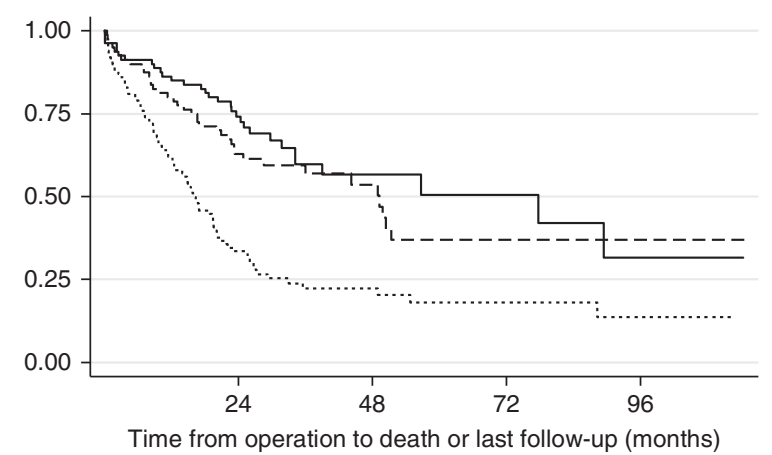

Number at risk

LNR1cat $=0 \quad 80$

$\begin{array}{lr}\text { LNR1cat }=1 & 80 \\ \text { LNR1cat }=2-4 & 100\end{array}$

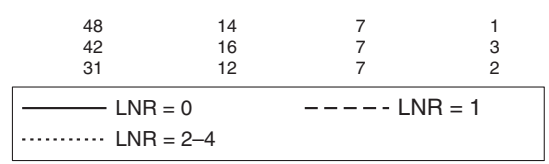

Figure 3. Overall survival of patients with extramural vascular invasion by LNR category (LNR 0, LNR 1 and LNR 2-4 together) undergoing curative colon cancer resection.
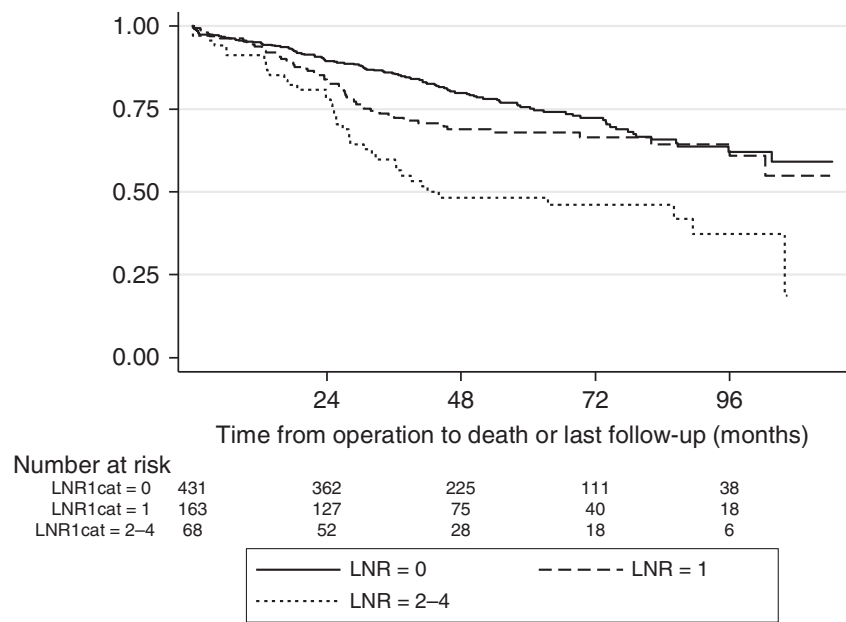

Figure 4. Overall survival of patients without extramural vascular invasion by LNR category (LNR 0, LNR 1 and LNR 2-4 together) undergoing curative colon cancer resection. 
resection. Different groups have used different methods for stratifying the LNR categories.

Schiffmann et al (2013), in a cohort of 142 stage III colon cancer patients, compared LNR with $\mathrm{pN}$ category. Using a single LNR statistical cutoff of 0.2 to separate patients into two groups, the authors concluded LNR did not improve the prognostic value in predicting survival. Limitations included the small number of patients and the variable preoperative staging strategy. No details of pathological assessment were given. Using only two groups for LNR may reduce its prognostic value.

Berger et al (2005) stratified patients with stage II and III colon cancer into four LNR categories based on quartiles. They demonstrated that LNR was an important predictor of overall survival when $>10$ lymph nodes were harvested. There were marked differences in the 5-year survival between the lowest and highest LNR categories for patients within the $\mathrm{pN} 1$ and $\mathrm{N} 2$ categories (19\% and 28\%, respectively).

From 1988 to 2003, Wang et al (2008) in a population-based study of 24477 patients with node-positive colon cancer from the Surveillance, Epidemiology and End Results cancer (SEER) registry demonstrated that LNR was a more accurate prognostic method for staging node-positive colon cancers than the number of positive lymph nodes. LNR was categorised based on four cutoff points: 1 out of $14,25 \%, 50 \%, 100 \%$. The results of this multi-centre study need to be interpreted with caution as the clinical and pathological techniques may change over time or vary between centres. In addition, not all treatment data were available, including the administration of adjuvant chemotherapy.

Rosenberg et al (2008), using statistical analysis, identified three cutoff values for $\operatorname{LNR}(0.17,0.41$ and 0.69$)$ and demonstrated superior prognostic impact on overall survival compared with $\mathrm{pN}$ category. There were some limitations to the study in that the study period covered 25 years (raising concerns regarding changes in pathological assessment over the time period) and colon and rectal cancers were analysed together. A follow-up of large populationbased study of colorectal cancer patients by the same leading author and using the same LNR cutoff values confirmed the strong independent prognostic value of these LNR categories (Rosenberg et al, 2010). There were marked differences in the 10 -year survival between the lowest and highest LNR categories for patients within the pN1 and $\mathrm{N} 2$ categories (20\% and 50\%, respectively). The authors concluded that LNR should be routinely included in the pathological reporting.

The present study, in a different patient population, used the same LNR cutoff values as Rosenberg et al (2008). This demonstrated the statistically significant difference in overall and disease-free survival using LNR categories from Rosenberg et al (2008) for patients undergoing curative colon cancer resection. The models including LNR category were found to have lower AIC values (indicating better model fit) than the models including $\mathrm{pN}$ category when predicting overall and disease-free survival. It is not possible to include both within the same scoring system due to the relationship between the categories; our results lend support to the view that LNR should be used instead of $\mathrm{pN}$ status. This has several advantages over other studies: surgical and pathological technique did not change, adjuvant chemotherapy was controlled for in the statistical model, and colon cancer was analysed separately.

The optimal total number of lymph nodes harvested for colon cancer resection is controversial. Despite the lack of evidence, The Royal College of Pathologists UK recommends a minimum of 12 lymph nodes need to be harvested (Williams et al, 2007). A number of observational studies have suggested different cutoffs for total number of lymph nodes to be harvested (Cianchi et al, 2002; Bui et al, 2006; Chen and Bilchik, 2006; Choi et al, 2010). O'Shea et al (2014) compared total lymph node yield of 3216 patients undergoing surgery for colorectal cancer. The authors demonstrated an increasing lymph node yield over time (14.91 in
2005 rising to 21.38 in 2012), but this was not associated with increased number of lymph node-positive cancers. Baxter et al (2010), in a population study of 11044 patients with pT3 colon cancers (SEER registry), reported that the proportion of patients found to be node positive increases with increasing total lymph node counts up to 5 or 6 but, at higher lymph node count $(\geqslant 7)$, has marginal effects on staging.

Sjo et al (2012), in an observational study, looked at the prognostic impact of total lymph node harvest and LNR in 950 patients undergoing curative colon cancer resection. The authors found that, on multivariate analysis, the total number of lymph nodes was not a prognostic factor when analysed with LNR for patients with lymph node metastasis. Also, Wang et al (2008) in the previously mentioned population-based study assessing patients with node-positive colon cancer concluded that the prognostic capability of LNR was not dependent on the total number of lymph nodes.

In the present study, $84 \%$ of patients had $>12$ lymph nodes harvested. On multivariate analysis, using the LNR model, the total number of lymph nodes harvested was not associated with overall survival or disease-free survival.

The presence of EMVI has been shown to be an adverse prognostic indicator of survival for patients with colorectal cancer. The majority of studies have focussed on node-negative colorectal cancers. Courtney et al (2009), in 378 patients undergoing potentially curative colorectal cancer resection, demonstrated that the presence of EMVI was associated with a significant decrease in survival. The authors did not perform any further analysis for patients with metastatic lymph nodes. Morris et al (2006), in a population-based study of 1306 patients with node-negative colonic carcinoma treated with surgery alone demonstrated a worse prognosis in the presence of EMVI. It is possible that these studies have concentrated on patients with node-negative colonic cancers as nodal disease is an indicator for adjuvant chemotherapy and the presence of EMVI is therefore unlikely to alter management in these patients. Sternberg et al (1999) assessed 171 patients with node-positive colorectal cancer and found that those patients without venous invasion had a better cancer-related survival compared with those with venous invasion. Stratifying patients to $\mathrm{pN} 1$ and $\mathrm{pN} 2$ lymph node categories did not show any significant cancer-related survival benefit. The authors concluded that venous invasion was a better indicator of prognosis than $\mathrm{pN}$ status. The authors assessed colon and rectal cancers together and the study did not control for administration of adjuvant chemotherapy. The differentiation between intramural and extramural venous invasion was not routinely made. Betge et al (2012) randomly selected 381 patients with colorectal cancer from 1992 to 2000. Differentiation between intramural and extramural venous invasion was made. EMVI was detected $14 \%$ of patients and a significant predictor of both disease progression and cancer-specific survival.

Quirke found in routine UK practice that the detection of EMVI was poor at $10 \%$ (Quirke and Morris, 2007). He felt that a pathologist should be able to detect EMVI in approximately $30 \%$ of cases. The Royal College of Pathologists have recommended that EMVI should be detected in at least $25 \%$ of cases (Williams et al, 2007).

In the present study, EMVI status was examined in all patients using the technique recommended by the Royal College of Pathologists. The incidence of EMVI in this study was $28 \%$. In this cohort of patients undergoing curative colon cancer resection, we have demonstrated that the presence of EMVI was a significant independent predictor of decreased overall survival and diseasefree survival even when adjusted for lymph node status.

A number of studies have found that patients with a low LNR have a similar long-term survival as node-negative patients. 
Moug et al (2011), in a study of 206 patients undergoing curative colorectal cancer patients, demonstrated that there was no statistically significant difference in overall survival between the two lowest LNR groups (pLNR $<0.05$ and pLNR 0.05-0.19). Patients in the pLNR category $<0.05$ were mainly node negative. The study did not control for adjuvant chemotherapy and did not assess for EMVI status. In a prospective nationwide Danish study of 8901 patients with Stage I-III colon cancer, the 5-year survival rate in LNR $<0.08$ was the same as those with node-negative disease (Lykke et al, 2013). It was not possible to differentiate between those patients receiving adjuvant chemotherapy.

In this study, which controlled for adjuvant chemotherapy, the presence of EMVI was associated with a worse prognosis regardless of lymph node status. For patients with or without EMVI, there was a similar statistically significant relationship between LNR categories as the overall sample. However, it was necessary to combine patients in LNR categories 2-4 due to smaller numbers. For patients without EMVI, those with low LNR (LNR1) have improved overall survival compared with those in the LNR 2-4 group. It may be that, on an individual basis for patients with a low LNR (0.01-0.17), adjuvant chemotherapy can be omitted in those deemed at risk of developing significant side effects as they have a relatively good prognosis.

This study has limitations. This was a retrospective review of routinely prospectively collected data. Although the overall number of patients in the study was reasonable, the number of patients in each lymph node category on sub-group analysis of EMVI status was small. The results of these subgroup analyses should only be interpreted as exploratory analyses.

\section{CONCLUSION}

This study has demonstrated, in the presence of consistently high surgical, pathological, oncological standards and long follow-up, the presence of EMVI and increasing LNR were independent predictors of adverse overall and disease-free survival in patients undergoing potentially curative colon cancer resection. LNR was superior to $\mathrm{pN}$ stage in predicting overall and disease-free survival. We believe that LNR and EMVI should be routinely included in the minimum data set for colon cancer pathological reporting. This would allow improved prognostic stratification (compared with TNM stage) and may help influence decisions on adjuvant chemotherapy for more frail patients.

\section{ACKNOWLEDGEMENTS}

There was no study funding. We are grateful to Tony Rafferty (Tailored Information for the People of Scotland, TIPs) for providing survival data.

\section{CONFLICT OF INTEREST}

The authors declare no conflict of interest.

\section{REFERENCES}

Baxter NN, Ricciardi R, Simunovic M, Urbach DR, Virnig BA (2010) An evaluation of the relationship between lymph node number and staging in pT3 colon cancer using population-based data. Dis Colon Rectum 53: 65-70.

Berger AC, Sigurdson ER, LeVoyer T, Hanlon A, Mayer RJ, Macdonald JS, Catalano PJ, Haller DG (2005) Colon cancer survival is associated with decreasing ratio of metastatic to examined lymph nodes. J Clin Oncol 23: 8706-8712.
Betge J, Pollheimer MJ, Lindtner RA, Komprat P, Schlemmer A, Rehak P, Vieth M, Hoefler G, Langner C (2012) Intramural and extramural vascular invasion in colorectal cancer: prognostic significance and quality of pathology reporting. Cancer 118: 628-638.

Bhangu A, Fitzgerald JEF, Slesser A, Northover JM, Faiz O, Tekkis P (2013) Prognostic significance of extramural vascular invasion in T4 rectal cancer. Colorectal Dis 15(11): e665-e671.

Bui L, Rempel E, Reeson D, Simunovic M (2006) Lymph node counts, rates of positive lymph nodes, and patient survival for colon cancer surgery in Ontario, Canada: a population-based study. J Surg Oncol 93(6): 439-445.

Chen SL, Bilchik AJ (2006) More extensive nodal dissection improves survival for stages I to III of colon cancer: a population-based study. Ann Surg 244(4): 602-610.

Choi HK, Law WL, Poon JT (2010) The optimal number of lymph nodes examined in stage II colorectal cancer and its impact of on outcomes. BMC Cancer 10: 267.

Cianchi F, Palomba A, Boddi V, Messerini L, Pucciani F, Perigli G, Bechi P, Cortesini C (2002) Lymph node recovery from colorectal tumor specimens: recommendation for a minimum number of lymph nodes to be examined. World J Surg 26(3): 384-389.

Courtney ED, West NJ, Kaur C, Ho J, Kalber B, Hagger R, Finlayson C, Leicester RJ (2009) Extramural vascular invasion is an adverse prognostic indicator of survival in patients with colorectal cancer. Colorectal Dis 11: $150-156$.

de Gramont A, Van Cutsem E, Schmoll HJ, Tabernero J, Clarke S, Moore MJ, Cunningham D, Cartwright TH, Hecht JR, Rivera F, Im SA, Bodoky G, Salazar R, Maindrault-Goebel F, Shacham-Shmueli E, Bajetta E, Makrutzki M, Shang A, Andre T, Hoff PM (2012) Bevacizumab plus oxaliplatin as adjuvant treatment for colon cancer (AVANT): a phase 3 randomised controlled trial. Lancet Oncol 13: 1225-1233.

Hohenberger W, Weber K, Matzel K, Papadopoulos T, Merkel S (2009) Standardized surgery for colonic cancer: complete mesocolic excision and central ligation-technical notes and outcome. Colorectal Dis 11: 354-365.

International Agency for Research on Cancer (2008) GLOBOCAN: Cancer Incidence, Mortality and Prevalence Worldwide (2008 Estimates). World Health Organization: Lyon, France.

Lykke J, Roikjaer O, Jess P. Danish Colorectal Cancer Group (2013) The relation between lymph node status and survival in stage I-III colon cancer: results from a prospective nationwide cohort study. Colorectal Dis 15: $559-565$.

Morris M, Platell C, de Boer B, McCaul K, Iacopetta B (2006) Populationbased study of prognostic factors in stage II colonic cancer. Br J Surg 93: 866-871.

Moug SJ, McColl G, Lloyd SM, Wilson G, Saldanha JD, Diament RH (2011) Comparison of positive lymph node ratio with an inflammation-based prognostic score in colorectal cancer. Br J Surg 98: 282-286.

O'Shea A, Aly O, Parnaby CN, Loudon MA, Samuel LM, Murray GI (2014) Increased lymph node yield in colorectal cancer is not necessarily associated with greater number of lymph node positive cancers. PLoS One 9: e104991.

Quirke P, Morris E (2007) Reporting colorectal cancer. Histopathology 50: 103-112.

Rosenberg R, Engel J, Bruns C, Hettland W, Hermes N, Jauch KW, Kopp R, Putterich E, Ruppert R, Schuster T, Friess H, Hulzel D (2010) The prognostic value of lymph node ratio in a population-based collective of colorectal cancer patients. Ann Surg 251: 1070-1078.

Rosenberg R, Friederichs J, Schuster T, Gertler R, Maak M, Becker K, Grebner A, Ulm K, Hofler H, Nekarda H, Siewert JR (2008) Prognosis of patients with colorectal cancer is associated with lymph node ratio. Ann Surg 248: 1067-1073.

Schiffmann L, Eiken AK, Gock M, Klar E (2013) Is the lymph node ratio superior to the Union for International Cancer Control (UICC) TNM in prognosis of colon cancer. World J Surg Oncol 11: 79.

SCOT-Short Course Oncology Therapy (2007) SCOT-Short Course Oncology Therapy: a study of adjuvant chemotherapy in colorectal cancer by the CACTUS and QUASAR 3 groups. Clinical trial.gov number NCT00749450.

Sjo OH, Merok MA, Svindland A, Nesbakken A (2012) Prognostic impact of lymph node harvest and lymph node ratio in patients with colon cancer. Dis Colon Rectum 55: 307-315.

Sobin LH, Wittekind Ch (eds): (1997) TNM Classification of Malignant Tumours, 5th edn. Wiley-Liss: New York, NY, USA. 
Sternberg A, Sibirsky O, Cohen D, Blemenson LE, Rodriguez-Bigas MA, Petrelli NJ (1999) New approach to the substaging of node-positive colorectal adenocarcinoma. Ann Surg Oncol 6: 161-165.

Ueno H, Mochizuki H, Akagi Y, Kusumi T, Yamada K, Ikegami M, Kawachi H, Kameoka S, Ohkura Y, Masaki T, Kushima R, Takahashi K, Ajioka Y, Hase K, Ochiai A, Wada R, Iwaya K, Shimazaki H, Nakamura T, Sugihara K (2012) Optimal colorectal cancer staging criteria in TNM classification. J Clin Oncol 30: 1519-1526.

Wang J, Hassett JM, Dayton MT, Kulaylat MN (2008) Lymph node ratio: role in the staging of node-positive colon cancer. Ann Surg Oncol 15: 1600-1608.
Williams GT, Quirke P, Shepherd NA (2007) Standards and Datasets for Reporting Cancers. Dataset for Colorectal Cancer, 2nd edn. Royal College of Pathologists: London, UK.

This work is published under the standard license to publish agreement. After 12 months the work will become freely available and the license terms will switch to a Creative Commons AttributionNonCommercial-Share Alike 4.0 Unported License 